\title{
Alterations of Endogenous Hormonal Levels in Plants under Drought and Salinity
}

\author{
Analía Llanes*\#, Andrea Andrade\#, Sergio Alemano, Virginia Luna* \\ Laboratorio de Fisiología Vegetal, Departamento de Ciencias Naturales, Facultad de Ciencias Exactas, \\ Físico-Químicas y Naturales, Universidad Nacional de Río Cuarto, Río Cuarto, Argentina \\ Email: "allanes@exa.unrc.edu.ar, "vluna@exa.unrc.edu.ar
}

Received 2 May 2016; accepted 15 July 2016; published 18 July 2016

Copyright (C) 2016 by authors and Scientific Research Publishing Inc.

This work is licensed under the Creative Commons Attribution International License (CC BY).

http://creativecommons.org/licenses/by/4.0/

(c) (;) Open Access

\begin{abstract}
The phytohormones are pivotal chemical messengers produced within the plant that regulate its growth and development, and responses to environmental stimuli. Drought and salinity are adverse environmental factors that disturb the plant hormonal balance. Accordingly, these hormonal fluctuations modify the cellular dynamic and hence they play a central role in regulating plant growth responses to abiotic stresses such as drought and salinity. The present review gives an update about the alterations of endogenous phytohormones such as abscisic acid (ABA), auxins (Aux), cytokinins (CKs), ethylene (ET), gibberellins (GAs), jasmonates (JAs), salicylic acid (SA), brassinosteroids (BRs), strigolactones (SLs) and nitric oxide (NO) that occur as part of the adaptative responses of plant against drought and salt stresses. Better understanding of the endogenous hormonal changes during the plant response to both abiotic stresses will contribute, in part, to the development of stress-tolerant plants.
\end{abstract}

\section{Keywords}

Drought, Plant Growth Responses, Phytohormones, Salinity

\section{Introduction}

Stressful environmental factors such as drought and salinity cause widespread crop losses throughout the world [1]. Both stresses affect more than $10 \%$ of arable land which causes approximately $50 \%$ decline in the average yields of major crops worldwide. In view of various climate change models, the scientists suggest that in several regions of the world, the crop losses due to increasing in water shortage and salinization of soils will further ag-

\footnotetext{
*Corresponding authors.

"These authors contributed equally to this manuscript.
}

How to cite this paper: Llanes, A., Andrade, A., Alemano, S. and Luna, V. (2016) Alterations of Endogenous Hormonal Levels in Plants under Drought and Salinity. American Journal of Plant Sciences, 7, 1357-1371. 
gravate its impact [2].

The acclimation of plants to drought and salt stresses is the result of different events leading to adaptive changes such as cellular homeostasis (ion homeostasis and osmotic adjustment), detoxification (neutralization of reactive oxygen species) and growth regulation [3]. [4] developed the concept of the "two-phase growth response to salinity", in which the first phase of growth reduction happened quickly (within minutes) after exposure to salinity due to the osmotic changes outside the root, causing modifications in cell-water relations (osmotic effect). The second effect is slower and it can take days, weeks or months, being the result of salt accumulation in leaves which lead to salt toxicity in plant (salt-specific effect). Based on this two-phase concept, the initial growth reduction for both salt-sensitive and salt-tolerant plants is caused by an osmotic effect of the salts in the medium outside the roots. By contrast, in the second phase, a salt-sensitive differs from a salt-tolerant species by its inability to prevent the salt accumulation to toxic levels. Nevertheless, some physiological plant responses to drought and salinity show high similarity and the components of both types of stresses interacting with each other, which ultimately results in cell dehydration and osmotic imbalance [5]. In fact, both drought and salinity (osmotic stresses) are often interconnected and they cause disruption of ion homeostasis and distribution, leading to arrest of plant growth, cell division and expansion. Consequently, plants have developed a wide range of adaptive responses, including morphological, anatomical, physiological, biochemical and molecular, allowing them to respond and properly adapt to drought and salinity [6] [7]. Thus, various tolerance mechanisms have been described on the basis of physiological modifications to overcome the harmful effects of drought and salt stresses. Among them, one of the most important is the alteration in endogenous phytohormone levels (Figure 1). It is well established that plant hormones modulate several responses during the whole plant life cycle both under stress and non-stress conditions [6]. The main phytohormones include ABA, GAs, CKs, Aux, ET, JAs, SA, BRs, SLs and NO. The regulation of plant growth responses by alterations in endogenous levels of above phytohormones in response to drought and salinity constitute the focus of this review.

\section{Effect of ABA on Plant Growth Responses under Drought and Salinity}

A huge amount of information had been accumulated on ABA. It has been documented that it is integrated into a complex signaling network that transcriptionally and post-translationally regulates several process of plant growth and development [8]. After germination, ABA temporarily delays the transition to the phase of seedling growth under unfavorable conditions, because it induces ABI5 protein accumulation, which would function as a checkpoint during early development to slow growth under adverse conditions [9]. Therefore, ABA is a key plant stress-signaling hormone and this role is an undisputed fact. Particularly, ABA is well known for conferring tolerance to abiotic stresses, among the most important are drought and salinity [10]. In response to drought, Arabidopsis plants synthesize ABA in the shoot which has been reported to be transported to the root [11]. It seems to be correlated with a higher ABA precursor (carotenoids) concentration in shoot than roots. The uptake, distribution and movement of ABA in different tissues of A. thaliana were analyzed by [12] who developed sensor proteins called "ABAleons". These biosensors revealed that the ABA concentration in guard cells increases when humidity is low, or when salt levels are high. Low water levels, or high salt levels, also slowly increased the concentration of ABA in the roots. The authors argument that this ABA increase may arise from an increment in ABA biosynthesis and/or a decrease in ABA breakdown. On this point, [13] showed that drought enhanced both ABA biosynthesis and catabolism, resulting in an increase of ABA and catabolites. For example, ABA increased in seedlings of sunflower $F_{3}$ tolerant families grown under water stress generated by $400 \mathrm{mM}$ mannitol, while in the sensitive families the ABA level was lower $\left(<500 \mathrm{pmol} \cdot \mathrm{g}^{-1} \mathrm{DW}\right)$. These findings suggest that constitutively high ABA levels in tolerant $\mathrm{F}_{3}$ families confer an advantage for these sunflower plants to cope with adverse conditions [14]. Similarly, [15] reported that drought (without irrigation) triggered an abrupt peak of ABA in both Kanlow and Greenville cv of Panicum virgatum L. (switchgrass) being higher in the tolerant Kanlow (11-fold) than in the sensitive Greenville (4.5-fold). However, the correlation between ABA endogenous level and stress-tolerance is not always positive. Thus, some native species from the arid regions display a plastic response to these environmental conditions. [16] showed that the highest ABA levels were found in the mesophytic plant Poa ligularis which is a native species from Patagonian Monte (Argentina). Remarkably, the xerophytic species Papostypa speciosa had the lowest ABA levels. Considering that ABA is a key hormone in regulating drought stress responses, the exposure of plants to salinity has been known to induce an increase in ABA levels. For example, ABA increased in leaves of salt stressed Brassica [17], Phaseolus vulgaris [18] and 


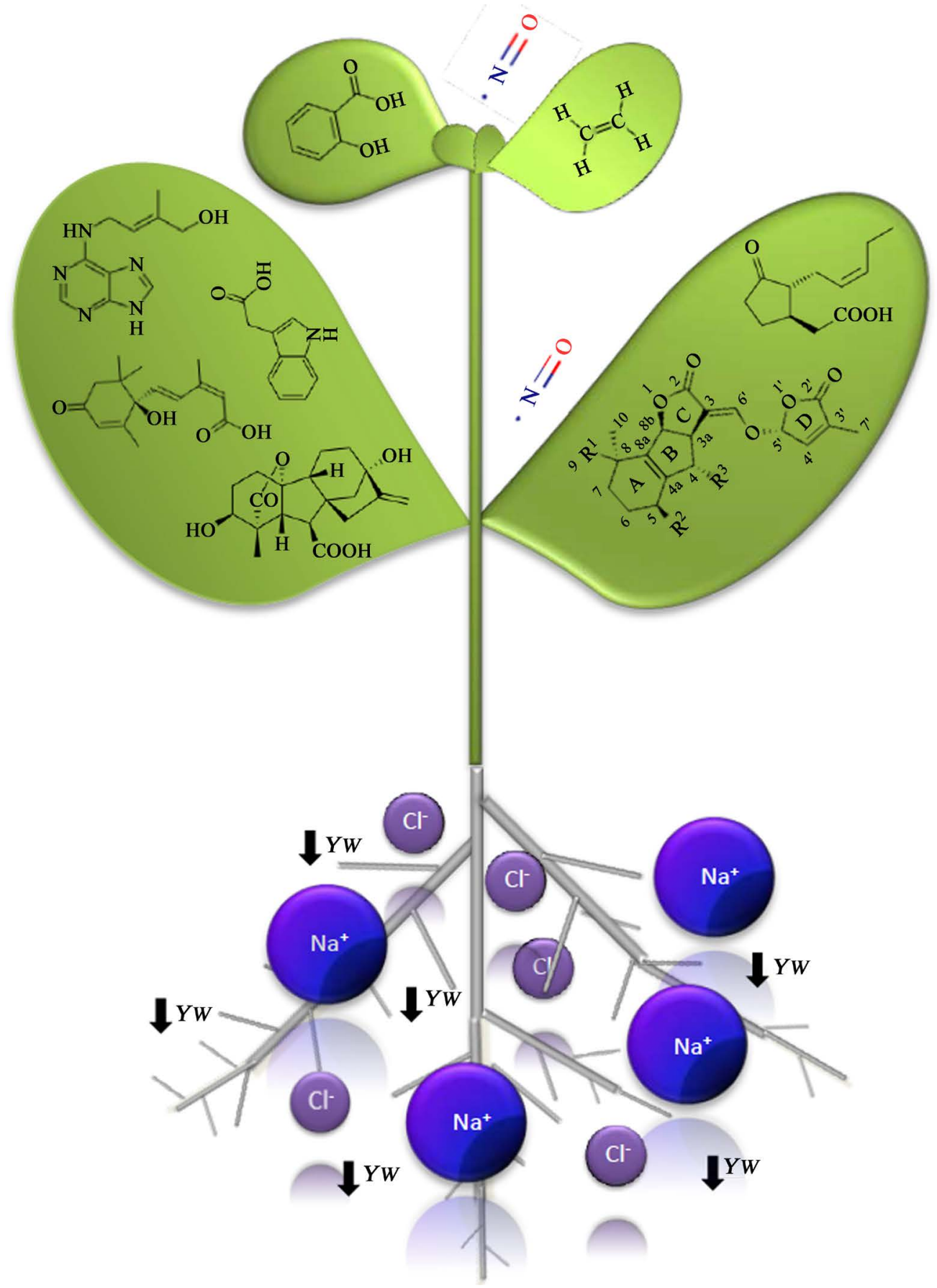

Figure 1. Chemical structures of phytohormones and roles they play in plant growing in adverse conditions, such as water and salt stresses. These compounds are multifunctional molecules playing several different roles in plant responses.

Zea mays [19]. Among the tools used to understand the mechanism of hormone action under abiotic conditions is the ABA application. Indeed, [20] reported that foliar ABA application $(15 \mu \mathrm{mol} / \mathrm{l})$ under salinity condition improved shoot dry matter, photosynthesis rate, peroxidase and catalase activity, and shoot $\mathrm{K}^{+}$concentration while decreased shoot $\mathrm{Na}^{+}$concentration in Okamer cv of canola, as consequence an increased salinity tolerance was observed; but ABA excess $(30 \mu \mathrm{mol} / \mathrm{l})$ reduced the growth in this cultivar. Moreover, the ABA level varied depending species, organ analyzed and age of plant as well as salt type and concentration. This assumption was reported in Prosopis strombulifera halophyte [21] [22]. The authors showed that endogenous ABA in leaves was 
higher than in roots showing the rapid biosynthesis and transport from roots. Indeed, an increase of ABA conjugate, ABA-glucose ester (ABA-GE), was found in both roots and leaves in salt-treated plants. Thus, these results suggest that ABA-GE and free ABA may act together to create a specific stress signal. In this review, we showed several studies confirming that ABA acts as a key mediator in plant responses to drought and salinity (Figure 2). However, the endogenous level of this hormone oscillate according to its biosynthesis, catabolism and transport through the plant, species and organ particular, duration and severity of both abiotic stresses.

\section{Effect of ET on Plant Growth Responses under Drought and Salinity}

In response to both drought and salinity there is often a significant increase in the ET production which has adverse effects on plant growth [23]. In general, the plants that produce low ET are more tolerant to the harmful effects of environmental stresses as compared to those that produce higher levels [24]. For example, the ET production differed significantly between two spring wheat cultivars, 8139 (with relatively low drought resistance) and 504 (with relatively high drought resistance) during water stress. The changes were higher in the drought-sensitive cv 8139 than in the drought-resistant cv 504 [25]. It appears that the high ET production in earlier period of water stress might be a signal helping to the plants to sense the stress condition, and to take some adaptative physiological response in advance. Interestingly, in response to salinity, ET appears to negatively affect salt tolerance because a correlation between increased 1-aminocyclopropane-1-carboxylic acid (ACC) levels and reduced salt tolerance was found in Arabidopsis. This phenomenon was opposite those observed in the ACC

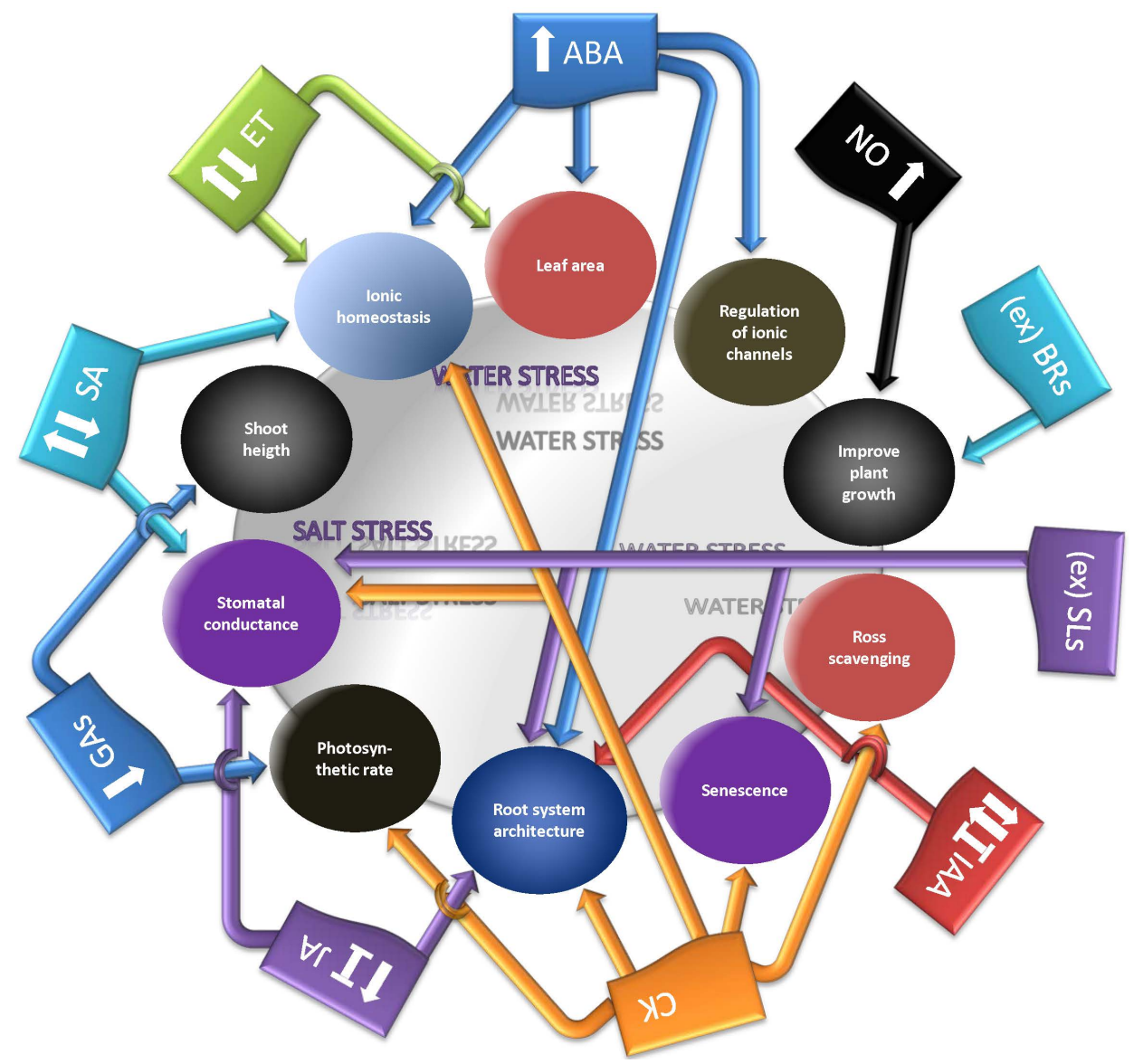

Figure 2. This figure summarizes the changes in the endogenous level of each hormone and its physiological effects mediating the plant responses to drought and salinity stresses. These changes in the hormonal level are represented by arrows inside of the each rectangle as follow: increases are shown by upward arrows ( $\uparrow$ ), decreases are shown by downward arrows ( $\downarrow$ ), whilst pointless arrows (I) indicate no change. Ex: exogenous applications of hormones. The circles represent the physiological effect associated with each phytohormone. ABA, abscisic acid; IAA, indole-3-acetic acid; CK, cytokinin; ET, ethylene; GAs, gibberellins; JA, jasmonic acid; SA, salicylic acid; BRs, brassinosteroids; SLs, strigolactones; NO, nitric oxide. 
synthase Arabidopsis mutant, acs7. The mutant showed an enhanced salt tolerance which suggests that ACS7 gene negatively regulates the salt tolerance though a low ET production [26]. By contrast, elevated ET production was found in the sst1 (soil salinity tolerant1) Arabidopsis mutant. The enhanced salt tolerance of this mutant seems to occur through an improved $\mathrm{Na}^{+} / \mathrm{K}^{+}$homeostasis resulting of the reduced root influx and shoot delivery of $\mathrm{Na}^{+}$[27] (Figure 2). Likewise, the use of an ACC oxidase (ACO) antisense in tomato plants confirmed the ET role under drought. In these plants, ET production was much lower than wild-type both under well-watered and drought. Thus, in response to drought a decrease in leaf growth was measured in wild-type but not in ACO antisense tomato plants [28] (Figure 2). Otherwise, in maize the ET production could not be correlated with reductions in leaf growth under drought [29]. Taking together, these studies suggest that ET may play a role in decreased leaf growth in some plant species and that ACC may be a long distance root-sourced signal under drought. Accordingly, both drought and salinity stresses can act on ET production and this phytohormone could have a negative or positive role in regulating plant stress-tolerance.

\section{Effect of JA on Plant Growth Responses under Drought and Salinity}

Traditionally, JAs have been associated with plant defense to biotic stresses. However, it is becoming increasingly evident that these compounds have direct and/or indirect roles in abiotic stresses. Thus, several researches showed that JAs levels were increased upon exposure to drought and salt stresses [30] [13]. Some studies demonstrated that JA accumulation during drought is not stable; for example, water-stressed soybean plants exhibited a transient increase in JA, followed by a decrease to below wild-type levels [31]. Nevertheless, in two Kanlow and Greenville cv of $P$. virgatum the JA level did not increase significantly in response to drought [15]. Despite of these fluctuations, in the literature there are numerous studies showing a JAs endogenous increase under abiotic stresses. For example, JA increased in spear tips of Asparagus officinalis [32], Carica papaya seedlings [33], Pinus pinaster plants [34], Oryza sativa leaves and roots [35] and citrumelo CPB 4475 (a commercial citrus rootstock) [36] exposed to drought. Similarly, under salinity, JA increased in salt-tolerant cv HF tomato from the beginning of salinization, while in salt-sensitive cv Pera it decreased after $24 \mathrm{~h}$ of treatment [37]. An increase in JA precursor the 12-oxo-phytodienoic acid (OPDA) and JA metabolite methylJA (MeJA) was observed in barley, tomato and A. thaliana plants treated with sorbitol or mannitol [38] [39]. Also, MeJA accumulation was reported in young panicles of rice plant overexpressing JA carboxyl methyl transferase gene (AtJMT) grown under severe drought [40]. These authors suggest that the MeJA accumulation may stimulate the ABA production. Recently, JA and OPDA were detected in seedlings of two sunflower (Helianthus annuus L.) inbred lines, B59 (drought-sensitive) and B71 (drought-tolerant) in response to water stress generated by mannitol. In both lines the stress produced a considerable increase in OPDA, and it was 3-fold higher in tolerant line. This finding suggests that OPDA might participate in the mechanisms that confer tolerance to water stress in B71 seedlings (Andrade, unpublished data). In concordance, [41] demonstrated that Arabidopsis plants producing higher OPDA levels exhibited a reduction in the stomatal aperture, and as result enhanced drought tolerance (Figure 2). It should be pointed out that this study confirmed OPDA as a drought-responsive regulator of stomatal closure which might act effectively together with $\mathrm{ABA}$ in this response. On the other hand, in response to salinity, [42] reported the detection of JA, OPDA, 11-hydroxyjasmonate (11-OH-JA), 12-hydroxyjasmonate (12-OH-JA) and MeJA in seedlings of tomato cv Moneymaker (wild-type) and its tss1, tss2 and tos1 mutants under $100 \mathrm{mM} \mathrm{NaCl}$ treatment. Interestingly, the mutant seedlings showed different patterns of JAs according to their differential hypersensitivity to abiotic stress. Likewise, in the halophyte $P$. strombulifera different endogenous levels of JAs (JA, OPDA, 11-OH-JA and 12-OH-JA) in roots and leaves treated with distinct salt treatments were observed. The 12-OH-JA level was higher in leaves than in roots in both control and treated plants, and this response may be the result of an active hydroxylation pathway in leaves or transport of root-generated 12-OH-JA [43]. In this regard, the occurrence of biosynthetic pathway of octadecanoic and jasmonates in roots was determined previously in cultures of tomato hairy root by [38] (Figure 2). This background exposes that the most family members of JAs would participate in abiotic stress tolerance. In spite of JA and MeJA were previously thought to be key regulators of JAs responses induced by stresses, it has been demonstrated that the isoleucine conjugate of JA (JA-Ile) acts in the signal transduction pathway of JA regulating stress-responses [44].

\section{Effect of SA on Plant Growth Responses under Drought and Salinity}

SA is a phytohormone of phenolic nature associated with biotic stress but in recent years there have been in- 
creasing reports about SA participation in the plant responses to abiotic stresses, among them drought and salinity [45]. In some cases, the endogenous SA levels increased. For example, in leaves of Phillyrea angustifolia L. SA increased progressively up to 5-fold during drought [46]. Similarly, leaves of soybean showed a significant increase of SA with the application of $8 \%$ and $16 \%$ of PEG during pre-flowering growth stage; however, this increase was insignificant during post-flowering growth stage [47]. Likewise, under salt stress the level of SA increased in rice seedlings [48]. In addition, SA increased in roots but it did not change in leaves of barley in response to water deficit [49]. Contrary, the drought caused a decrease of SA in drought-sensitive sunflower $\mathrm{F}_{3}$ seedlings compared to control [14]. Also, SA level has been shown to decrease with salinity in Iris hexagona [50]. Recently, [15] reported that SA level was not modified by water stress in drought-tolerant cv Kanlow of $P$. virgatum while it decreased in drought-sensitive cv Greenville. These studies above mentioned demonstrated that the endogenous SA level is a plastic response due to it is modified according to organ, ontogenetic stage, particular species and type of stress. Moreover, [51] informed that SA accumulation may play a protective role during water stress through the regulation of SA-inducible PR1 and PR2 genes. Nevertheless, some studies showed that the SA accumulation aggravated the salinity negative effects. Indeed, transgenic NahG Arabidopsis lines under $\mathrm{NaCl}$ treatment accumulated SA and they displayed impairment in photosynthesis, which was counteracted by the decrease of SA due to nahG mutation [52]. In coincidence, the high SA level observed in $\mathrm{Na}_{2} \mathrm{SO}_{4}$-treated $P$. strombulifera plants was correlated with a failure in ion compartmentalization (Figure 2). In addition, low humidity conditions (30\% RH) accentuated the salt stress effect and increased SA. These responses indicate that SA accumulation is not a protective hormonal signal but rather a signal of injury in $P$. strombulifera under adverse conditions [21]. In spite of the SA involvement in plant responses to abiotic stress, it is not yet clear its role regulating the drought and salinity tolerance because some studies have reported the improved stress tolerance by SA accumulation whereas others have demonstrated less stress tolerance when the endogenous SA level remain high.

\section{Effect of GAs on Plant Growth Responses under Drought and Salinity}

GAs are other important group of phytohormones and its central role in the response to abiotic stress is becoming increasingly evident. The plant growth reduction under both drought and salinity may be due, at least in part, to lower production of GAs or to the inability of the plant to respond to this hormone. Thus, several studies showed that under drought the endogenous GAs levels markedly decreased because this stress appeared to inhibit the GA biosynthesis and/or increase its degradation. Early reports demonstrated that drought reduced the GAs accumulation in lettuce [53], cottonwood saplings [54] and in rice grains during early grain filling [55]. Similarly, in leaves of unstressed and water stressed maize seedlings showed that $\mathrm{GA}_{3}$ decreased considerably during drought [56]. More recent evidences support the endogenous GAs changes produced by drought. For example, $\mathrm{GA}_{3}$ levels were markedly reduced in shoots of common bean with increasing levels of drought when compared with those of control (80\% hold water capacity) [57]. Furthermore, [58] also found that in Lupinus albus the drought gradually declined the GAs levels. Similarly, in transgenic plants of Populus tremula х Populus alba a decrease in GAs caused inhibition of primary growth (e.g., height and number of internodes) under drought [59]. These studies above demonstrate that the reduction of GA levels and signaling has been shown to contribute to plant growth restriction on exposure to drought as well as salinity (Figure 2). In response to salinity, [60] reported that salt-treated Arabidopsis plants showed a decrease in bioactive GAs levels. Modifications of GAs levels may be involved in adjustment of plants under limiting environmental conditions and maintains source-sink relation, leading to an increase in sucrose in source leaves, with a decrease in photosynthesis rate by feedback inhibition responses [61] (Figure 2). The concentration and chemical composition of the salts present in the soil modulate the GAs metabolism. This fact was reported in the $P$. strombulifera halophyte under different salt treatments. The roots showed a high $\mathrm{GA}_{4}$ level in $\mathrm{NaCl}$ treatment. In leaves, a 5-fold increase respect to control was determined at $-1.9 \mathrm{MPa}$ in correlation with optimum growth for this species. Also $\mathrm{GA}_{1}$ level was significantly increased ( 3.5 fold at $-1.9 \mathrm{MPa}$ ) in both organs, indicating that both GAs play a role in controlling shoot growth. Under $\mathrm{Na}_{2} \mathrm{SO}_{4}\left(-2.6 \mathrm{MPa}\right.$ ) was observed the lowest levels of $\mathrm{GA}_{4}$ and $\mathrm{GA}_{1}$ in coincidence with the maximum growth inhibition related to sulfate toxic effect [22]. Therefore, these results suggest that differential growth responses to both salts would be mediated, at least in part, by modifications in $\mathrm{GA}_{1}$ and $\mathrm{GA}_{4}$ levels. In summary, the evidences are accumulating that reduction of GAs endogenous levels is a general response to abiotic stress. However, the action of GAs cannot be considered in isolation of the other hormone signals be- 
cause of the rapidly emerging evidence for crosstalk between hormonal signaling pathways. Moreover, a deep understanding of GAs regulating the abiotic stress responses would be an important step towards improving plant growth under adverse environmental conditions.

\section{Effect of Aux on Plant Growth Responses under Drought and Salinity}

The participation of Aux in stress responses has been deduced from observations that genes associated with Aux signaling pathways are stimulated in plants expose to different abiotic stresses [62]. Under drought, controversial results have been reported regarding the endogenous levels of indole-3-acetic acid (IAA). For example, an increased IAA level was observed in response to drought in maize roots [63] and sunflower plants [64]. In addition, during a prolonged drought, a significant increase of IAA was observed in lower and middle leaves and roots of Nicotiana tabacum L. wild-type and transgenic SAG12::ZOG1, 35S::ZOG1 and 35S:P5CSF129A plants [65]. On the contrary, [66] found that drought resulted in a decrease of IAA level in leaves of wheat. [67] reported that the leaf IAA level decreased during drought and no difference in this hormone was found between both tall fescue cultivars, Van Gogh (relatively drought-tolerant) and AST7002 (relatively drought-sensitive). Therefore, to date there is no generalized response about how IAA levels oscillate in water-stressed plants. Nevertheless, some studies showed that the application of IAA was positively correlated with drought tolerance. For example, the indole-3-butyric acid application increased endogenous IAA level which improved the drought tolerance in tall fescue [68]. Likewise, in Arabidopsis, the activation of YUCCA7 and YUCCA6 [69] gene, encoding a flavin monooxygenase belonging to the tryptophan-dependent auxin biosynthetic pathway, resulted in elevated endogenous Aux levels and enhanced drought tolerance. Recently, [70] reported alterations of IAA levels according to drought severity in rice leaves. Thus, under slight drought IAA level had no significant change, after moderate drought stress IAA level was reduced to about 81\%, and after severe drought stress the level of this Aux was reduced to $72 \%$ of the control. The salinity stress induces an Aux accumulation in Arabidopsis and its redistribution to the root tip, resulting in the primary root growth inhibition, a marked reduction in lateral root primordia formation, and significantly increases in the elongation of existing lateral roots [71] (Figure 2). Thus, these results suggest that Aux transport appears to be essential for the adaptive remodeling of root system architecture under salinity. Indeed, roots of $P$. strombulifera halophyte accumulated IAA under salt treatments [22]. The highest IAA levels were in concordance with an increase of lateral root formation in this specie confirming that IAA may be associated with an enlarged root system under salinity. This response also was observed after the IAA application. For example, [72] reported that the IAA application had a highly stimulatory effect on the root and shoot growth of wheat seedlings under salt conditions. Interestingly, [73] showed differences in endogenous IAA levels in expanding leaves and roots of two maize cultivars. The salt-resistant genotype significantly increased IAA levels in leaves and maintained its concentration in roots. This background exposes the involvement of Aux in the regulation of plant physiological responses under both drought and salinity. However, there is a remaining information gap to properly understand the role of endogenous Aux in plant grown in adverse environmental conditions.

\section{Effect of CK on Plant Growth Responses under Drought and Salinity}

Likewise to Aux, CKs have been traditionally associated with developmental processes; however, in the last years it has proposed a relevant participation of this hormone in drought and salinity plant responses. Against theses stresses CKs may help the plants to resist. Thus, several studies show beneficial effects of an increase in CKs levels associated with the stomatal conductance, transpiration and photosynthesis under water stress [74]. In addition, a decrease in CKs levels and signaling suppression was found in alfalfa under drought [75] but it was accompanied with accelerated senescence (Figure 2). This response was used by plants to adapt to drought. In this regard, [76] demonstrated that among the most physiologically active CKs, the tZ-type CKs rather than the iP-type CKs, act as negative regulators in drought response in Arabidopsis. Moreover, the authors proposed that CKs levels reduction enhance survival rates of the CK-deficient plants by minimizing water loss. Similarly, under salinity some reports have demonstrated that the endogenous levels and transport of CKs were also reduced in several plant species [77]. Studies with the halophytes Suaea depressa and S. maritima suggested that CKs applications may emphasize the symptoms associated with salt stress [78]. It should be pointed out that this response could be the result of the action of CKs on stimulating stomatal opening, thus facilitating transpiration and therefore magnifying the effect of salinity. Likewise, [22] showed a low endogenous CKs level in leaves of 
NaCl-treated $P$. strombulifera plants, which was correlated with a low transpiration, probably as a result of synthesis or transport decreased of CKs from the roots. On the contrary, the leaves of $\mathrm{Na}_{2} \mathrm{SO}_{4}$-treated plants showed an accumulation of CKs, which may explain the high transpiration in these plants. Taken together, these reports demonstrate a controversial role of endogenous CKs in response to both drought and salinity (Figure 2). Thus, molecular approaches could be useful to contribute to knowledge about the CKs role in both abiotic stresses. For example, [79] working with two approaches assessed whether specific root-localized transgenic IPT (a key enzyme for CKs biosynthesis) gene expression could substantially improve tomato plant growth and yield under salinity. The authors demonstrated that enhancing root CKs synthesis modified the shoot hormonal and ionic status, thus ameliorating salinity-induced decreases in growth and yield. In concordance, tobacco plants showing root specifically increased cytokinindehydrogenase/oxidase (CKX) gene expression, indicated that overexpression of CKX1 is linked to greater root system and dwarf shoots improving the salt stress-tolerance [80]. However, a more in-depth understanding on the CK functioning/signaling mechanisms is required to allow us to explore its possible role in alleviating the adverse effects of drought and salinity.

\section{Effect of BRs on Plant Growth Responses under Drought and Salinity}

BRs are a group of steroidal phytohormones that play pivotal roles in wide range of developmental phenomena as well as in plant responses to abiotic stress [81]. In view of some reports, it is evident that BRs application improves growth and yield of some species (Figure 2). In this regard, the application of BRs was reported to induce stress-related genes expression, which results in the maintenance of photosynthesis activity, activation of antioxidant enzymes, accumulation of osmoprotectants, and induction of other hormonal responses [82]. Particularly, the BRs treatment compensated the biomass reduction in sugar-beet plants caused by mild drought [83]. The BRs treatment has also been reported to increase seedling growth of Sorghum vulgare under osmotic stress [84], and improve the drought tolerance in Phaseolus vulgaris [85]. Also, [86] found that in rice the BRs application improved the leaf water economy and $\mathrm{CO}_{2}$ assimilation, and enabled it to withstand drought. In addition, it has been shown that the treatment with other BR, 24-epibrassinolide (24-EBR) increased the survival rate of $A$. thaliana and Brassica napus seedlings subjected to drought stress [87]. Similarly, the exogenous application of BRs can also alleviate the adverse effects of the salinity. [88] reported that 28-homobrassinolide (28-HomoBL) spray to the foliage or supply through roots of Brassica juncea plants generated from the seeds soaked in $\mathrm{NaCl}$ enhanced the growth and seed yield under normal conditions. However, this compound has no effect on cell ultrastructure but significantly reduced the damage induced by salt stress on chloroplast. Also, the application of this compound significantly increased the pigment levels in several species under salinity [89]. This response may be associated to an effect of BRs on transcription and/or translation in the synthesis of pigments. Likewise, 24-EBR significantly enhanced the growth and photosynthetic capacity of salt-tolerant and salt-sensitive wheat plants [90]. As above, although exogenous BRs has been reported to improve the plant resistance to several abiotic stresses, there are controversies about the mode of action of endogenous BRs in plant stress responses. Interestingly, [91] working on BR mutants lkb (a BR-deficient mutant) and lka (a BR-perception mutant), and on wild-type pea plants showed that BRs level did not increase under drought and impaired in BRs biosynthesis or signaling had no influences on drought-stress tolerance. Accordingly, these authors argued that endogenous BRs are not participating of the plant stress responses. Besides the question remains if exogenous vs. endogenous BRs have different roles in drought and salinity, or whether the role of BRs is species-specific. Therefore, future studies can be warranted to elucidate the mechanism by which endogenous BRs levels regulate both drought and salinity responses.

\section{Effect of SLs on Plant Growth Responses under Drought and Salinity}

SLs are multifunctional compounds recognized as a new class of phytohormones that controls different processes in plants. Their biosynthesis has been suggested to occur throughout the plant, although at low or even undetectable levels [92]. The SLs occurrence has been demonstrated in a wide variety of plant species, including dicots and monocots, in which different types of these compounds have been found (reviewed by [92]). Because they are still relatively unknown phytohormones its mode of action in response to abiotic stress has been studied mainly through the exogenous application. Thus, a comparison of SL-deficient and SL-response max Arabidopsis mutants subjected to drought with or without SLs applications revealed that the drought-sensitive phenotype of the $\max 3$ and $\max 4$ mutants could be rescued when they were sprayed with SLs. Furthermore, SL-treated 
wild-type Arabidopsis plants were more tolerant to drought than the untreated plants [93]. It seems to support the role of SLs as a positive regulator of plant response to drought. In addition, it has been proposed that endogenous SLs may positively modulate both drought and salt stress responses through ABA-dependent and ABA-independent pathways. This complexity is reflected in the functions of ABA, CKs, and SLs on the regulation of stomatal closure and leaf senescence [94] (Figure 2). Also, [95] demonstrated the potential use of genetic engineering to improve the drought and salt tolerance of plants by manipulating the endogenous SLs levels and/or SLs signaling. However, the question of which SLs are active endogenously has not been resolved. Moreover, up to date scarce knowledge is available about how the endogenous SLs levels vary in response to drought and salinity.

\section{Effect of NO on Plant Growth Responses under Drought and Salinity}

NO is being now classified as a novel phytohormone regulating the plant growth and development as well as the plant responses to abiotic stresses [96]. This fact is supported because an increase in NO production has been generally reported when plants were subjected to stresses [97]. For example, drought-induced NO production has been reported in many plant species, including pea, wheat and tobacco [98]. Also, an increase of endogenous NO level via application of exogenous NO donor (sodium nitroprusside, SNP) has been shown to confer resistance to drought and salinity [99]. [100] reported in cucumber seedling subjected to water deficit (5 to $10 \mathrm{~h}$ at the stage of the third fully expanded leaf) a slight NO production in cells of root tips and in the surrounding elongation zone compared with $17 \mathrm{~h}$ of water deficit, which resulted in a high increase in NO production. Under both stress conditions, drought or salinity, NO could act as an antioxidant and activator of reactive oxygen species (ROS) scavenging enzymes, as well as inductor of certain stress-related genes increasing the plant resistance [96]. Therefore, an increase in antioxidant enzyme activities and reduced ROS accumulation in rat neuronal NO synthase (nNOS) transgenic Arabidopsis plants confirmed that in vivo NO reduces drought-triggered oxidative stress and thereby the cell damage [101]. Similar to NO role in antioxidant activity in response to drought, some studies support the same NO role during the salinity tolerance. In this regard, [99] showed that exogenous NO application induce antioxidant enzymes activity, promote the maintenance of the cellular redox homeostasis and mitigate the oxidative damage produced by salt stress. Moreover, there is some experimental evidence that pre-exposure to NO efficiently protect plants to salinity. Thus, NO-associated salt priming action was an enhanced tolerance of both halophytes and glycophytes to salinity during germination and early seedling stages after pre-exposure of their seeds to NO donors [102]. Arabidopsis mutant (Atnoa1) plants with an impaired in vivo NO synthase (NOS) activity exhibit hypersensitivity to salinity [103]. Therefore, these reports suggest that NO participates in signaling responses against salinity. Several experiments using NO donors and NO inhibitors indicated that NO acts as a signal in inducing salt tolerance by increasing the $\mathrm{Na}^{+} / \mathrm{K}^{+}$ratio, which was dependent on increased plasma membrane $(\mathrm{PM}) \mathrm{H}^{+}$-ATPase as well as vacuolar $(\mathrm{V}) \mathrm{H}^{+}$-ATPase and $\mathrm{H}^{+}$-PPase activities. In spite of the literature above mentioned that confirmed the involvement of NO in response to drought and salt stresses, more studies should be carried out to demonstrate how vary the NO production and its mode of action.

\section{Conclusions and Perspectives}

In this review, we highlight several experimental evidences on the variability in hormonal responses to both drought and salinity, although it is clear that these responses share common components that are likely working in different organs or tissues of whole plant either individually or in concert. Unravelling new mode of action of the different phytohormones is promising. A figure summarizing the changes in the endogenous hormone level and its physiological effects mediating the drought and salinity responses is depicted in Figure 2. More recently, the mechanisms underlying the crosstalk among different phytohormones signaling pathways have been described, leading to the elucidation of partial or entire crosstalk hormonal cascades. Whereas most plant hormonal studies are based on exogenous applications and/or the genetic and biotechnological tools in order to elucidate the phytohormones role in response to drought and salinity, the knowledge about how the endogenous hormone levels are modified in response to both stresses during plant growth still remains scarce.

\section{References}

[1] Agarwal, P.K., Shukla, P.S., Gupta, K. and Jha, B. (2013) Bioengineering for Salinity Tolerance in Plants: State of the 
Art. Molecular Biotech, 54, 102-123. http://dx.doi.org/10.1007/s12033-012-9538-3

[2] Anjum, S.A., Xie, X., Wang, L., Saleem, M.F., Man, C. and Lei, W. (2011) Morphological, Physiological and Biochemical Responses of Plants to Drought Stress. African Journal of Agricultural Research, 6, 2026-2032.

[3] Frary, A., Gol, D., Keles, D., Okmen, B., Pinar, H., Sigva, H., Yemenicioglu, A. and Doganlar, S. (2010) Salt Tolerance in Solanum pennellii: Antioxidant Response and Related QTL. BMC Plant Biology, 10, 58-59. http://dx.doi.org/10.1186/1471-2229-10-58

[4] Munns, R., James, R.A. and Läuchli, A. (2006) Approaches to Increasing the Salt Tolerance of Wheat and Other Cereals. Journal of Experimental Botany, 57, 1025-1043. http://dx.doi.org/10.1093/jxb/erj100

[5] Jakab, G., Ton, J., Flors, V., Zimmerli, L., Métraux, J.P. and Mauch-Mani, B. (2005) Enhancing Arabidopsis Salt and Drought Stress Tolerance by Chemical Riming for Its Abscisic Acid Responses. Plant Physiology, 139, 67-74. http://dx.doi.org/10.1104/pp.105.065698

[6] Ahmadi, S.H., Andersen, M.N., Plauborg, F., Poulsen, R.T., Jensen, C.R., Sepaskhah, A.R. and Hansen, S. (2010) Effects of Irrigation Strategies and Soils on Field Grown Potatoes: Yield and Water Productivity. Agricultural Water Management, 97, 1923-1930. http://dx.doi.org/10.1016/j.agwat.2010.07.007

[7] Fatma, M., Iqbal, M., Khan, R., Masood, A. and Khan, N.A. (2013) Coordinate Changes in Assimilatory Sulfate Reduction Is Correlated to Salt Tolerance: Involvement of Phytohormones. Annual Review \& Research in Biology, 3, 267-295.

[8] Tanaka, Y., Sugano, S.S., Shimada, T. and Hara Nishimura, I. (2013) Enhancement of Leaf Photosynthetic Capacity through Increased Stomatal Density in Arabidopsis. New Phytologist, 198, 757-764. http://dx.doi.org/10.1111/nph.12186

[9] López-Molina, L., Mongrand, S. and Chua, N.H. (2001) A Postgermination Developmental Arrest Checkpoint Is Mediated by Abscisic Acid and Requires the ABI5 Transcription Factor in Arabidopsis. Proceedings of the National Academy of Sciences of the United States of America, 98, 4782-4787. http://dx.doi.org/10.1073/pnas.081594298

[10] Wasilewska, A., Vlad, F., Sirichandra, C., Redko, Y., Jammes, F., Valon, C., Freidit, F.N. and Leung, J. (2008) An Update on Abscisic Acid Signaling in Plants and More. Molecular Plant, 1, 198-217. http://dx.doi.org/10.1093/mp/ssm022

[11] Geng, Y., Wu, R., Wee, C.W., Xie, F., Wei, X., Chan, P.M., Tham, C., Duan, L. and Dinneny, J.R. (2013) A SpatioTemporal Understanding of Growth Regulation during the Salt Stress Response in Arabidopsis. Plant Cell, 25, 21322154. http://dx.doi.org/10.1105/tpc.113.112896

[12] Waadt, R., Hitomi, K., Nishimura, N., Hitomi, C., Adams, S.R., Getzoff, E.D. and Schroeder, J.I. (2014) FRET-Based Reporters for the Direct Visualization of Abscisic Acid Concentration Changes and Distribution in Arabidopsis. eLife, 3, e01739. http://dx.doi.org/10.7554/elife.01739

[13] Huang, D., Wu, W., Abrams, S.R. and Cutler, A.J. (2008) The Relationship of Drought-Related Gene Expression in Arabidopsis thaliana to Hormonal and Environmental Factors. Journal of Experimental Botany, 11, 2991-3007. http://dx.doi.org/10.1093/jxb/ern155

[14] Fernández, C., Alemano, S., Vigliocco, A., Andrade, A. and Abdala, G. (2012) Stress Hormone Levels Associated with Drought Tolerance vs. Sensitivity in Sunflower (Helianthus annuus L.). In: Nafees, K., Rahat, N., Noushina, I. and Naser, A., Eds., Phytohormones and Abiotic Stress Tolerance in Plants, Springer, Berlin, 249-276. http://dx.doi.org/10.1007/978-3-642-25829-9_11

[15] Aimar, D., Calafat, M., Andrade, A., Carassay, L., Bouteau, F., Abdala, G. and Molas, L. (2014) Drought Effects on the Early Development Stages of Panicum virgatum L.: Cultivar Differences. Biomass \& Bioenergy, 66, 49-59. http://dx.doi.org/10.1016/j.biombioe.2014.03.004

[16] Cenzano, A.M., Masciarelli, O. and Luna, M.V. (2014) Abscisic Acid Metabolite Profiling as Indicators of Plastic Responses to Drought in Grasses from Arid Patagonian Monte (Argentina). Plant Physiology and Biochemistry, 83, 200-206. http://dx.doi.org/10.1016/j.plaphy.2014.07.024

[17] He, T. and Cramer, G.R. (1996) Abscisic Acid Concentrations Are Correlated with Leaf Area Reductions in Two Salt-Stressed Rapid-Cycling Brassica Species. Plant and Soil, 179, 25-33. http://dx.doi.org/10.1007/BF00011639

[18] Cabot, C., Sibole, J.V., Barcelo, J. and Poschenrieder, C. (2009) Abscisic Acid Decreases Leaf $\mathrm{Na}^{+}$Exclusion in Salt-Treated Phaseolus vulgaris L. Plant Growth Regulation, 28, 187-192. http://dx.doi.org/10.1007/s00344-009-9088-5

[19] Cramer, G.R. and Quarrie, S.A. (2002) Abscisic Acid Is Correlated with the Leaf Growth Inhibition of Four Genotypes of Maize Differing in Their Response to Salinity. Functional Plant Biology, 29, 111-115. http://dx.doi.org/10.1071/PP01131

[20] Farhoudi, R. and Saeedipour, S. (2011) Effect of Exogenous Abscisic Acid on Antioxidant Activity and Salt Tolerance in Rapeseed (Brassica napus) Cultivars. Research on Crops, 12, 122-130. 
[21] Devinar, G., Llanes, A., Masciarelli, O. and Luna, V. (2013) Abscisic Acid and Salicylic Acid Levels Induced by Different Relative Humidity and Salinity Conditions in the Halophyte Prosopis strombulifera. Plant Growth Regulation, 70, 247-256. http://dx.doi.org/10.1007/s10725-013-9796-5

[22] Llanes, A., Masciarelli, O., Ordoñez, R., Isla, M.I. and Luna, V. (2014) Differential Growth Responses to Sodium Salts Involve Different ABA Catabolism and Transport in the Halophyte Prosopis strombulifera. Biologia Plantarum, 58, 80-88. http://dx.doi.org/10.1007/s10535-013-0365-6

[23] Ali, S., Charles, T.C. and Glick, B.R. (2012) Delay of Flower Senescence by Bacterial Endophytes Expressing 1-Aminocyclopropane-1-Carboxylate Deaminase. Journal of Applied Microbiology, 113, 1139-1144. http://dx.doi.org/10.1111/j.1365-2672.2012.05409.x

[24] Leonard, R.T., Nell, T.A. and Hoyer, L. (2005) Response of Potted Rose Varieties to Short-Term Ethylene Exposure. In: van Meeteren, U., Marissen, N. and van Doorn, W.G., Eds., 8th International Symposium on Postharvest Physiology of Ornamental Plants, Doorwerth, 10 August 2003, 373-380. http://dx.doi.org/10.17660/ActaHortic.2005.669.49

[25] Kun-Ming, C., Hai-Jun, G., Guo-Cang, C. and Cheng-Lie, Z. (2002) ACC and MACC Biosynthesis and Ethylene Production in Water-Stressed Spring Wheat. Acta Botanica Sinica, 44, 775-781.

[26] Proust, H., Hoffmann, B., Xie, X., Yoneyama, K., Schaefer, D.G. and Yoneyama, K. (2011) Strigolactones Regulate Protonema Branching and Act as a Quorum Sensing-Like Signal in the Moss Physcomitrella patens. Development, 138, 1531-1539. http://dx.doi.org/10.1242/dev.058495

[27] Jiang, C., Belfield, E.J., Cao, Y., Smith, J.A. and Harberd, N.P. (2013) An Arabidopsis Soil-Salinity-Tolerance Mutation Confers Ethylene-Mediated Enhancement of Sodium/Potassium Homeostasis. Plant Cell, 25, 3535-3552. http://dx.doi.org/10.1105/tpc.113.115659

[28] Sobeih, W.Y., Dodd, I.C., Bacon, M.A., Grierson, D. and Davies, W.J. (2004) Long-Distance Signals Regulating Stomatal Conductance and Leaf Growth in Tomato (Lycopersicon esculentum) Plants Subjected to Partial Root-Zone Drying. Journal of Experimental Botany, 55, 2353-2363. http://dx.doi.org/10.1093/jxb/erh204

[29] Voisin, A.S., Reidy, B., Parent, B., Rolland, G., Redondo, E., Gerentes, D., Tardieu, F. and Muller, B. (2006) Are ABA, Ethylene or Their Interaction Involved in the Response of leaf Growth to Soil Water Deficit? An Analysis Using Naturally Occurring Variation or Genetic Transformation of ABA Production in Maize. Plant Cell and Environment, 29, 1829-1840. http://dx.doi.org/10.1111/j.1365-3040.2006.01560.x

[30] Kang, D.J., Seo, Y.J., Lee, J.D., Ishii, R., Kim, K.U., Shin, D.H. and Lee, I.J. (2005) Jasmonic Acid Differentially Affects Growth, Ion Uptake and Abscisic Acid Concentration in Salt-Tolerant and Salt-Sensitive Rice Cultivars. Journal of Agronomy and Crop Science, 191, 273-282. http://dx.doi.org/10.1111/j.1439-037X.2005.00153.x

[31] Creelman, R.A. and Mullet, J.E. (1995) Jasmonic Acid Distribution and Action in Plants: Regulation during Development and Response to Biotic and Abiotic Stress. Proceedings of the National Academy of Sciences, 92, 4114-4119. http://dx.doi.org/10.1073/pnas.92.10.4114

[32] Gapper, N.E., Norris, G.E., Clarke, S.F., Lill, R.E. and Jameson, P.E. (2002) Novel Jasmonate Amino Acid Conjugates in Asparagus officinalis during Harvest-Induced and Natural Foliar Senescence. Physiologia Plantarum, 114, 116-124. http://dx.doi.org/10.1034/j.1399-3054.2002.1140116.x

[33] Mahouachi, J., Arbona, V. and Gómez-Cadenas, A. (2007) Hormonal Changes in Papaya Seedlings Subjected to Progressive Water Stress and Re-Watering. Plant Growth Regulation, 53, 43-50. http://dx.doi.org/10.1007/s10725-007-9202-2

[34] Pedranzani, H., Sierra-de-Grado, R., Vigliocco, A., Miersch, O. and Abdala, G. (2007) Cold and Water Stresses Produce Changes in Endogenous Jasmonates in Two Populations of Pinus pinaster Ait. Plant Growth Regulation, 52, 111116. http://dx.doi.org/10.1007/s10725-007-9166-2

[35] Du, H., Liu, H. and Xiong, L. (2013) Endogenous Auxin and Jasmonic Acid Levels Are Differentially Modulated by Abiotic Stresses in Rice. Frontiers in Plant Science, 4, 389-397. http://dx.doi.org/10.3389/fpls.2013.00397

[36] de Ollas, C., Hernando, B., Arbona, V. and Gómez-Cadenas, A. (2013) Jasmonic Acid Transient Accumulation Is Needed for Abscisic Acid Increase in Citrus Roots under Drought Stress Conditions. Physiologia Plantarum, 147, 296306. http://dx.doi.org/10.1111/j.1399-3054.2012.01659.x

[37] Pedranzani, H., Racagni, G., Alemano, S., Miersch, O., Ramírez, I., Peña-Cortés, H., Taleisnik, E., Machado-Domenech, E. and Abdala, G. (2003) Salt Tolerant Tomato Plants Show Increased Levels of Jasmonic Acid. Plant Growth Regulation, 41, 149-158. http://dx.doi.org/10.1023/A:1027311319940

[38] Abdala, G., Miersch, O., Kramell, R., Vigliocco, A., Agostini, E., Forchetti, G. and Alemano, S. (2003) Jasmonate and Octadecanoid Occurrence in Tomato Hairy Roots. Endogenous Level Changes in Response to NaCl. Plant Growth Regulation, 40, 21-27. http://dx.doi.org/10.1023/A:1023016412454

[39] Seltmann, M.A., Stingl, N.E., Lautenschlaeger, J.K., Krischke, M., Mueller, M.J. and Berger, S. (2010) Differential Impact of Lipoxygenase 2 and Jasmonates on Natural and Stress-Induced Senescence in Arabidopsis. Plant Physiology, 
152, 1940-1950. http://dx.doi.org/10.1104/pp.110.153114

[40] Kim, E.H., Kim, Y.S., Park, S.-H., Koo, Y.J., Choi, Y.D., Chung, Y.-Y., Lee, I.-J. and Kim, J.-K. (2009) Methyl Jasmonate Reduces Grain Yield by Mediating Stress Signals to Alter Spikelet Development in Rice. Plant Physiology, 149, 1751-1760. http://dx.doi.org/10.1104/pp.108.134684

[41] Savchenko, T., Kolla, V.A., Wang, C.-Q., Nasafi, Z., Hicks, D.R., Phadungchob, B., Chehab, W.E., Brandizzi, F., Froehlich, J. and Dehesh, K. (2014) Functional Convergence of Oxylipin and Abscisic Acid Pathways Controls Stomatal Closure in Response To Drought. Plant Physiology, 164, 1151-1160. http://dx.doi.org/10.1104/pp.113.234310

[42] Andrade, A., Vigliocco, A., Alemano, S., Miersch, O., Botella, M.A. and Abdala, G. (2005) Endogenous Jasmonates and Octadecanoids in Hypersensitive Tomato Mutants during Germination and Seedling Development in Response to Abiotic Stress. Seed Science Research, 15, 309-318. http://dx.doi.org/10.1079/SSR2005219

[43] Reginato, M., Abdala, G., Miersch, O., Ruiz, O., Moschetti, E. and Luna, V. (2012) Changes in the Levels of Jasmonates and Free Polyamines Induced by Na2SO 4 and $\mathrm{NaCl}$ in Roots and Leaves of the Halophyte Prosopis strombulifera. Biologia, 67, 689-697. http://dx.doi.org/10.2478/s11756-012-0052-7

[44] Pauwels, L., Barbero, G.F., Geerinck, J., Tilleman, S., Grunewald, W. and Perez, A.C. (2010) NINJA Connects the Co-Repressor Topless to Jasmonate Signaling. Nature, 464, 788-791. http://dx.doi.org/10.1038/nature08854

[45] Hayat, Q., Hayat, S., Irfan, M. and Ahmad, A. (2010) Effect of Exogenous Salicylic Acid under Changing Environment: A Review. Environmental and Experimental Botany, 68, 14-25. http://dx.doi.org/10.1016/j.envexpbot.2009.08.005

[46] Munné-Bosch, S. and Peñuelas, J. (2003) Photo and Antioxidative Protection, and a Role for Salicylic Acid during Drought and Recovery in Field-Grown Phillyrea angustifolia Plants. Planta, 217, 758-766. http://dx.doi.org/10.1007/s00425-003-1037-0

[47] Hamayun, M., SohanSohan, E.Y., Khan, S.A. and Shinwari, Z.K. (2010) Silicon Alleviates the Adverse Effects of Salinity and Drought Stress on Growth and Endogenous Plant Growth Hormones of Soybean (Glycine max L.). Pakistan Journal of Botany, 42, 1713-1722.

[48] Sawada, H., Shim, I.S. and Usui, K. (2006) Induction of Benzoic Acid 2-Hydroxylase and Salicylic Acid Biosynthesis Modulation by Salt Stress in Rice Seedlings. Plant Science, 171, 263-270. http://dx.doi.org/10.1016/j.plantsci.2006.03.020

[49] Bandurska, H. and Stroiński, A. (2005) The Effect of Salicylic Acid on Barley Response to Water Deficit. Acta Physiologiae Plantarum, 27, 379-386. http://dx.doi.org/10.1007/s11738-005-0015-5

[50] Wang, Y., Mopper, S. and Hasenstein, K.H. (2001) Effects of Salinity on Endogenous Levels of ABA, IAA, JA, and SA in Iris hexagona. Journal of Chemical Ecology, 27, 327-342. http://dx.doi.org/10.1023/A:1005632506230

[51] Miura, K., Okamoto, H., Okuma, E., Shiba, H., Kamada, H., Hasegawa, P.M. and Murata, Y. (2013) SIZ1 Deficiency Causes Reduced Stomatal Aperture and Enhanced Drought Tolerance via Controlling Salicylic Acid-Induced Accumulation of Reactive Oxygen Species in Arabidopsis. The Plant Journal, 73, 91-104. http://dx.doi.org/10.1111/tpj.12014

[52] Hao, L., Wang, Y., Xu, J., Feng, S.-D., Ma, C.-Y., Liu, C., Xu, X., Li, G.-Z. and Herbert, S.J. (2011) Role of endogenous Salicylic Acid in Arabidopsis Response to Elevated Sulfur Dioxide Concentration. Biologia Plantarum, 55, 297-304. http://dx.doi.org/10.1007/s10535-011-0042-6

[53] Aharoni, N., Blumenfeld, A. and Richmond, A.E. (1977) Hormonal Activity Detached Lettuce Leaves as Affected by Leaf Water Content. Plant Physiology, 59, 1169-1173. http://dx.doi.org/10.1104/pp.59.6.1169

[54] Rood, S.B., Zanewich, K., Stefura, C. and Mahoney, J.M. (2000) Influence of Water Table Decline on Growth Allocation and Endogenous Gibberellins in Black Cottonwood. Tree Physiology, 20, 831-836. http://dx.doi.org/10.1093/treephys/20.12.831

[55] Yang, J.C., Zhang, J.H., Wang, Z.Q., Zhu, Q.S. and Wang, W. (2001) Hormonal Changes in the Grains of Rice Subjected to Water Stress during Grain Filling. Plant Physiology, 127, 315-323. http://dx.doi.org/10.1104/pp.127.1.315

[56] Wang, L., Huang, Z., Baskin, C.C., Baskin, J.M. and Dong, M. (2008) Germination of Dimorphic Seeds of the Desert Annual Halophyte Suaeda aralocaspica (Chenopodiaceae), a C4 Plant without Kranz Anatomy. Annals of Botany, 102, 757-769. http://dx.doi.org/10.1093/aob/mcn158

[57] Abass, S. and Mohamed, H. (2011) Alleviation of Adverse Effects of Drought Stress on Common Bean (Phaseolus vulgaris L.) by Exogenous Application of Hydrogen Peroxide. Bangladesh Journal of Botany, 40, 75-83. http://dx.doi.org/10.3329/bjb.v40i1.8001

[58] Abdalla, M.M. (2011) Beneficial Effects of Diatomite on the Growth, the Biochemical Contents and Polymorphic DNA in Lupinus albus Plants Grown under Water Stress. Agriculture and Biology Journal of North America, 2, 207220. http://dx.doi.org/10.5251/abjna.2011.2.2.207.220 
[59] Zawaski, C. and Busov, V.B. (2014) Roles of Gibberellin Catabolism and Signaling in Growth and Physiological Response to Drought and Short-Day Photoperiods in Populus trees. PLoS ONE, 20, 9-e862179. http://dx.doi.org/10.1371/journal.pone.0086217

[60] Achard, P., Cheng, H., De Grauwe, L., Decat, J., Schoutteten, H. and Moritz, T. (2006) Integration of Plant Responses to Environmentally Activated Phytohormonal Signals. Science, 311, 91-94. http://dx.doi.org/10.1126/science.1118642

[61] Iqbal N., Nazar R., Khan M.I.R., Masood A. and Khan N.A. (2011) Role of Gibberellins in Regulation of Source-Sink Relations under Optimal and Limiting Environmental Conditions. Current Science, 100, 998-1007.

[62] Coupe, S.A., Palmer, B.G., Lake, J.A., Overy, S.A., Oxborough, K. and Woodward, F.I. (2006) Systemic Signalling of Environmental Cues in Arabidopsis Leaves. Journal of Experimental Botany, 57, 329-341. http://dx.doi.org/10.1093/jxb/erj033

[63] Xin, Z.Y., Zhou, X. and Pilet, P.E. (1997) Level Changes of Jasmonic, Abscisic, and Indole-3yl-Acetic Acids in Maize under Desiccation Stress. Journal of Plant Physiology, 151, 120-124. http://dx.doi.org/10.1016/S0176-1617(97)80047-8

[64] Masia, A., Pitacco, A., Braggio, L. and Giulivo, C. (1994) Hormonal Responses to Partial Drying of the Root System of Helianthus annuus L. Journal of Experimental Botany, 45, 69-76. http://dx.doi.org/10.1093/jxb/45.1.69

[65] Dobra, J., Motyka, V., Dobrev, P., Malbeck, J., Prasil, I.T., Haisel, D. and Vankova, R. (2010) Comparison of Hormonal Responses to Heat, Drought and Combined Stress in Tobacco Plants with Elevated Proline Content. Journal of Plant Physiology, 167, 1360-1370. http://dx.doi.org/10.1016/j.jplph.2010.05.013

[66] Xie, Z., Kasschau, K. and Carrington, J. (2003) Negative Feedback Regulation of Dicer-Like1 in Arabidopsis by microRNA-Guided mRNA. Current Biology, 13, 784-789. http://dx.doi.org/10.1016/S0960-9822(03)00281-1

[67] Man, H.M., Pollmann, S., Weiler, E.W. and Kirby, E.G. (2011) Increased Glutamine in Leaves of Poplar Transgenic with Pine GS1 a Caused Greater Anthranilate Synthetase Alpha-Subunit (ASA1) Transcript and Protein Bundances: An Auxin-Related Mechanism for Enhanced Growth in GS Transgenics? Journal of Experimental Botany, 62, 44234431. http://dx.doi.org/10.1093/jxb/err026

[68] Zhang, H., Tan, G., Wang, Z., Yang, J. and Zhang, J. (2009) Ethylene and ACC Levels in Developing Grains Are Related to the Poor Appearance and Milling Quality of Rice. Plant Growth Regulation, 58, 85-96. http://dx.doi.org/10.1007/s10725-008-9354-8

[69] Kim, J., Patterson, S.E. and Binder, B.M. (2013) Reducing Jasmonic Acid Levels Causes Ein2 Mutants to Become Ethylene Responsive. FEBS Letters, 587, 226-230. http://dx.doi.org/10.1016/j.febslet.2012.11.030

[70] Du, H., Liu, H. and Xiong, L. (2013) Endogenous Auxin and Jasmonic Acid Levels Are Differentially Modulated by Abiotic Stresses in Rice. Frontiers in Plant Science, 4, 389-397. http://dx.doi.org/10.3389/fpls.2013.00397

[71] Wang, H., Liang, X., Wan, Q., Wang, X. and Bi, Y. (2009) Ethylene and Nitric Oxide Are Involved in Maintaining Ion Homeostasis in Arabidopsis callus under Salt Stress. Planta, 230, 293-307. http://dx.doi.org/10.1007/s00425-009-0946-y

[72] Javid, M.G., Sorooshzadeh, A., Moradi, F., Sanavy, S.A. and Allahdadi, I. (2011) The Role of Phytohormones in Alleviating Salt Stress in Crop Plants. Australian Journal of Crop Science, 5, 726-734.

[73] Zörb, C., Geilfus, C.M., Mühling, K. and Ludwing-Müller, J. (2013) The Influence of Salt Stress on ABA and Auxin Concentrations in Two Maize Cultivars Differing in Salt Resistance. Journal of Plant Physiology, 170, $220-224$. http://dx.doi.org/10.1016/j.jplph.2012.09.012

[74] Pospíšilová, J. (2003) Participation of Phytohormones in the Stomatal Regulation of Gas Exchange during Water Stress. Biologia Plantarum, 46, 491-506. http://dx.doi.org/10.1023/A:1024894923865

[75] Riefler, M., Novak, O., Strnad, M. and Schmulling, T. (2006) Arabidopsis Cytokinin Receptor Mutants Reveal Functions in Shoot Growth, Leaf Senescence, Seed. Size, Germination, Root Development, and Cytokinin Metabolism. Plant Cell, 18, 40-54. http://dx.doi.org/10.1105/tpc.105.037796

[76] Nishiyama, R., Watanabe, Y., Fujita, Y., Le, D.T., Kojima, M., Werner, T., Vankova, R., Yamaguchi-Shinozaki, K., Shinozaki, K., Kakimoto, T., Sakakibara, H., Schmülling, T. and Tran, L.S. (2011) Analysis of Cytokinin Mutants and Regulation of Cytokinin Metabolic Genes Reveals Important Regulatory Roles of Cytokinins in Drought, Salt and Abscisic Acid Responses, and Abscisic Acid Biosynthesis. Plant Cell, 23, 2169-2183. http://dx.doi.org/10.1105/tpc.111.087395

[77] Argueso, C.T., Ferreira, F.J. and Kieber, J.J. (2009) Environmental Perception Avenues: The Interaction of Cytokinin and Environmental Response Pathways. Plant, Cell \& Environment, 32, 1147-160. http://dx.doi.org/10.1111/j.1365-3040.2009.01940.x

[78] Boucaud, J. and Ungar, I.A. (1976) Hormonal Control of Germination under Saline Conditions of Three Halophyte Taxa in Genus Suaeda. Plant Physiology, 36, 197-200. 
[79] Ghanem, M.E., Albacete, A. and Smigocki, A.C. (2011) Root-Synthesized Cytokinins Improve Shoot Growth and Fruit Yield in Salinized Tomato (Solanum lycopersicum L.) Plants. Journal of Experimental Botany, 62, 125-140. http://dx.doi.org/10.1093/jxb/erq266

[80] Macková, J., Vasková, M., Macek, P., Hronková, M., Schreiber, L. and Santrücek, J. (2013) Plant Response to Drought Stress Simulated by ABA Application: Changes in Chemical Composition of Cuticular Waxes. Environmental and Experimental Botany, 86, 70-75. http://dx.doi.org/10.1016/j.envexpbot.2010.06.005

[81] Choudhary, S.P., Yu, J.Q., Yamaguchi-Shinozaki, K., Shinozaki, K. and Tran, L.S. (2012) Benefits of Brassinosteroid Crosstalk. Trends in Plant Science, 17, 594-605. http://dx.doi.org/10.1016/j.tplants.2012.05.012

[82] Divi, U., Rahman, T. and Krishna, P. (2010) Brassinosteroid-Mediated Stress Tolerance in Arabidopsis Shows Interactions with Abscisic Acid, Ethylene and Salicylic Acid Pathways. BMC Plant Biology, 10, 151-161. http://dx.doi.org/10.1186/1471-2229-10-151

[83] Schilling, G., Schiller, C. and Otto, S. (1991) Influence of Brassinosteroids on Organ Relation and Enzyme Activities of Sugar-Beet Plants. In: Cutler, H.G., Yokota, T. and Adam, G., Eds., Brassinosteroids: Chemistry, Bioactivity and Applications, American Chemical Society, Washington DC, 208-219. http://dx.doi.org/10.1021/bk-1991-0474.ch018

[84] Vardhini, B.V. and Rao, S.S.R. (2003) Amelioration of Osmotic Stress by Brassinosteroids on Seed Germination and Seedling Growth of Three Varieties of Sorghum. Plant Growth Regulation, 41, 25-31. http://dx.doi.org/10.1023/A:1027303518467

[85] Upreti, K.K. and Murti, G.S. (2004) Effects of Brassinosteroids on Growth, Nodulation, Phytohormone Content and Nitrogenase Activity in French Bean under Water Stress. Biologia Plantarum, 48, 407-411. http://dx.doi.org/10.1023/B:BIOP.0000041094.13342.1b

[86] Farooq, M., Wahid, A., Basra, S.M.A. and Din, I.D. (2009) Improving Water Relations and Gas Exchange with Brassinosteroids in Rice under Drought Stress. Journal of Agronomy and Crop Science, 195, 262-269. http://dx.doi.org/10.1111/j.1439-037X.2009.00368.x

[87] Kagale, S., Divi, U.K., Krochko, J.E., Keller, W.A. and Krishna, P. (2007) Brassinosteroid confers tolerance in Arabidopsis thaliana and Brassica napus to a range of abiotic stresses. Planta, 225, 353-364. http://dx.doi.org/10.1007/s00425-006-0361-6

[88] Hayat, S., Ali, B., Hassan, S.A. and Ahmad, A. (2007) Brassinosteroids Enhanced Antioxidantsunder Cadmium Stress in Brassica juncea. Environmental and Experimental Botany, 60, 33-41. http://dx.doi.org/10.1016/j.envexpbot.2006.06.002

[89] Hassan, W.M., Almaghraby, O.A. and Sakr, M.M. (2008) Effect of Sowing Dates and Vernalization on Beta vulgaris cv Univers Growth, Anatomy and Some Chemical Components of the Root. Agricultural Research Journal, Suez Canal University, 8, 41-47.

[90] Shahbaz, M., Ashraf, M. and Athar, H.R. (2008) Does Exogenous Application of 24-Epibrassinolide Ameliorate Salt Induced Growth Inhibition in Wheat (Triticum aestivum L.)? Plant Growth Regulation, 55, 51-64. http://dx.doi.org/10.1007/s10725-008-9262-y

[91] Jager, C.E., Symons, G.M., Nomura, T., Yamada, Y., Smith, J.J., Yamaguchi, S., Kamiya, Y., Weller, J.L., Yokota, T. and Reid, J.B. (2008) Characterization of Two Brassinosteroid C-6 Oxidase Genes in Pea. Plant Physiology, 143, 1894-1904. http://dx.doi.org/10.1104/pp.106.093088

[92] Xie, Z., Kasschau, K. and Carrington, J. (2003) Negative Feedback Regulation of Dicer-Like1 in Arabidopsis by microRNA-Guided mRNA. Current Biology, 13, 784-789. http://dx.doi.org/10.1016/S0960-9822(03)00281-1

[93] Van Ha, C., Leyva-González, M.A., Osakabe, Y., Tran, U.T., Nishiyama, R., Watanabe, Y., Tanaka, M., Seki, M., Yamaguchi, S., Dong, N.V., Yamaguchi-Shinozaki, K., Shinozaki, K., Estrella, L.H. and Phan Tran, L.S. (2013) Positive Regulatory Role of Strigolactone in Plant Responses to Drought and Salt Stress. Proceedings of the National Academy of Sciences of the United States of America, 111, 851-856. http://dx.doi.org/10.1073/pnas.1322135111

[94] Czarnecki, O., Yang, J., Weston, D., Tuskan, G. and Chen, J. (2013) A Dual Role of Strigolactones in Phosphate Acquisition and Utilization in Plants. International Journal of Molecular Sciences, 14, 7681-7701. http://dx.doi.org/10.3390/ijms14047681

[95] Foo, E. and Reid, J.B. (2013) Strigolactones: New Physiological Roles for an Ancient Signal. Journal of Plant Growth Regulation, 32, 429-442. http://dx.doi.org/10.1007/s00344-012-9304-6

[96] Siddiqui, M.H., Al-Whaibi, M.H. and Basalah, M.O. (2010) Role of Nitric Oxide in Tolerance of Plants to Abiotic Stress. Protoplasma, 248, 447-455. http://dx.doi.org/10.1007/s00709-010-0206-9

[97] Cantrel, C., Vazquez, T., Puyaubert, J., Rezé, N., Lesch, M., Kaiser, W.M., Dutilleul, C., Guillas, I., Zachowski, A. and Baudouin, E (2011) Nitric Oxide Participates in Cold-Responsive Phosphosphingo Lipid Formation and gene Expression in Arabidopsis thaliana. New Phytologist, 189, 415-427. http://dx.doi.org/10.1111/j.1469-8137.2010.03500.x 
[98] Kolbert, Z., Bartha, B. and Erdei, L. (2005) Generation of Nitric Oxide in Roots of Pisum sativum, Triticum aestivum and Petroselinum crispum Plants under Osmotic and Drought Stress. Acta Biologica Szegediensis, 49, 13-16.

[99] Tanou, G., Job, C., Rajjou, L., Arc, E., Belghzi, M., Diamantidis, G., Molassiotis, A. and Job, D. (2009) Proteomics Reveal the Overlapping Roles of Hydrogen Peroxide and Nitric Oxide in the Acclimation of Citrus Plants to Salinity. The Plant Journal, 60, 795-804. http://dx.doi.org/10.1111/j.1365-313X.2009.04000.x

[100] Arasimowicz-Jelonek, M., Floryszak-Wieczorek, J. and Kubis, J. (2009) Involvement of Nitric Oxide in Water Stress-Induced Responses of Cucumber Roots. Plant Science, 177, 682-690. http://dx.doi.org/10.1016/j.plantsci.2009.09.007

[101] Shi, H., Ye, T., Zhu, J.K. and Chan, Z. (2014) Constitutive Production of Nitric Oxide Leads to Enhanced Drought Stress Resistance and Extensive Transcriptional Reprogramming in Arabidopsis. Journal of Experimental Botany, 65, 4119-4131. http://dx.doi.org/10.1093/jxb/eru184

[102] Molassiotis, A., Tanou, G. and Diamantidis, G. (2010) NO Says More than 'YES' to Salt Tolerance: Salt Priming and Systemic Nitric Oxide Signaling in Plants. Plant Signaling and Behavior, 5, 209-212. http://dx.doi.org/10.4161/psb.5.3.10738

[103] Zhao, B., Liu, K., Zhang, H., Zhu, Q. and Yang, J. (2007) Causes of Poor Grain Plumpness of Two Line Hybrids and Their Relationships to the Contents of Hormones in Rice Grain. Agricultural Sciences in China, 6, 930-940.

http://dx.doi.org/10.1016/S1671-2927(07)60131-X

\section{Submit or recommend next manuscript to SCIRP and we will provide best service for you:}

Accepting pre-submission inquiries through Email, Facebook, Linkedin, Twitter, etc A wide selection of journals (inclusive of 9 subjects, more than 200 journals)

Providing a 24-hour high-quality service

User-friendly online submission system

Fair and swift peer-review system

Efficient typesetting and proofreading procedure

Display of the result of downloads and visits, as well as the number of cited articles

Maximum dissemination of your research work

Submit your manuscript at: http://papersubmission.scirp.org/ 